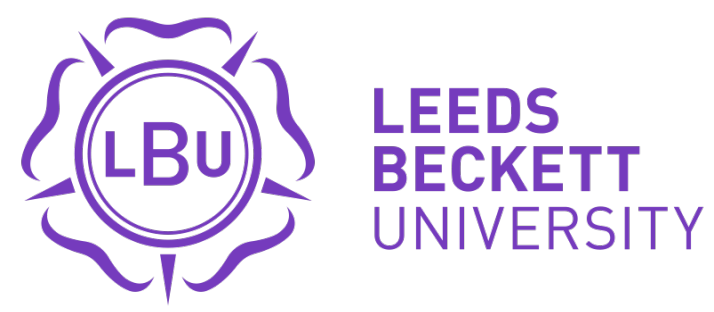

Citation:

Schöffl, I and Wustenfeld, J and Jones, G and Dittrich, S and Lutter, C and Schöffl, V (2021) Cardiopulmonary exercise tests of adolescent elite sport climbers-a comparison of the German junior national team in sport climbing and Nordic skiing. Health Promotion \& Physical Activity, 14 (1). pp. 1-8. ISSN 2544-9117

Link to Leeds Beckett Repository record:

https://eprints.leedsbeckett.ac.uk/id/eprint/7727/

Document Version:

Article (Published Version)

Creative Commons: Attribution-Noncommercial 4.0

The aim of the Leeds Beckett Repository is to provide open access to our research, as required by funder policies and permitted by publishers and copyright law.

The Leeds Beckett repository holds a wide range of publications, each of which has been checked for copyright and the relevant embargo period has been applied by the Research Services team.

We operate on a standard take-down policy. If you are the author or publisher of an output and you would like it removed from the repository, please contact us and we will investigate on a case-by-case basis.

Each thesis in the repository has been cleared where necessary by the author for third party copyright. If you would like a thesis to be removed from the repository or believe there is an issue with copyright, please contact us on openaccess@leedsbeckett.ac.uk and we will investigate on a case-by-case basis. 


\title{
Cardiopulmonary exercise tests of adolescent elite sport climbers - a comparison of the German junior national team in sport climbing and Nordic skiing
}

\author{
Isabelle Schöff|',2,3A-G, Jan Wüstenfeld ${ }^{4-D, G}$, Gareth Jones ${ }^{3 \mathrm{G}}$, \\ Sven Dittrich ${ }^{1 C, D, G}$, Chris Lutter $^{5 C, D, G}$, Volker Schöff| $\left.\right|^{2,3,6,7 A-G}$ \\ ${ }^{1}$ Department of Pediatric Cardiology, Friedrich-Alexander-Universität Erlangen-Nürnberg, Germany \\ ${ }^{2}$ Section of Sportsmedicine and Sports Orthopaedics, Department of Orthopedic and Trauma Surgery, Klinikum Bamberg, Germany \\ ${ }^{3}$ School of Clinical and Applied Sciences, Leeds Beckett University, UK \\ ${ }^{4}$ Insitute for Applied Exercise Science, University Leipzig, Germany \\ ${ }^{5}$ Department of Orthopaedics, University Hospital Rostock, Germany \\ ${ }^{6}$ Department of Emergency Medicine, Section Wilderness Medicine, University of Colorado School of Medicine, Denver, USA \\ ${ }^{7}$ Department of Traumatology and Orthopedic Surgery, Friedrich-AlexanderUniversity, Erlanger-Nüremberg, Germany
}

$A$ - the preparation of the research project

$B$ - the assembly of data for the research undertaken

$C$ - the conducting of statistical analysis

$D$-interpretation of results

E-manuscript preparation

$F$-literature review

$G$-final approval of the version to be published

\section{Article history:}

Received: 02.02.2021

Accepted: 15.02 .2021

Published: 25.02.2021

\begin{abstract}
Introduction: All the research investigating the cardiopulmonary capacity in climbers is focused on predictors for climbing performance. The effects of climbing on the cardiovascular system in adolescents climbing at an elite level (national team) have not been evaluated. Material and methods: Retrospective analysis of the cardiopulmonary exercise test (CPET) performed on a cycle ergometer during the annual medical examination of the entire German Junior National climbing team on one occasion and for a selected subgroup on two occasions spaced two years apart. The data from the subgroup was compared to an age- and gender-matched control of Nordic skiers from the German Junior National Nordic skiing team. Results: 47 climbers (20 girls, 27 boys) were examined once. The $V \mathrm{O}_{2 \text { peak }}$ achieved by the athletes was $41.3 \mathrm{~mL} \mathrm{~kg}^{-1} \mathrm{~min}^{-1}$ (boys) and $39.8 \mathrm{~mL} \mathrm{~kg}^{-1} \mathrm{~min}^{-1}$ (girls). 8 boys and 6 girls were tested twice over a period of 27.5 months. The parameters of the exercise test measured on both occasions were significantly lower than those of the 8 male and 6 female Nordic skiers. There was no change with respect to any variables (e.g. $V \mathrm{O}_{2 \text { peak }}$, peak work load, peak heart rate, peak lactate or $\mathrm{O}_{2}$ pulse) over the examined period. Conclusions: The elite climbers investigated in this study showed comparable $V \mathrm{O}_{2 \text { peak }}$ values to athletes from team and combat sports. The Nordic skiers to which they were compared showed significantly higher values consistant with the fact that this is an endurance sport. Even though the cardiopulmonary measurements of the Nordic skiers still improved after two years of training, no adaptations could be observed in the elite climbers.
\end{abstract}

Keywords: cardiopulmonary exercise testing, adolescent athlete, $\mathrm{VO}_{2 \text { peak }}$, cardiopulmonary capacity in climbing
"Address for correspondence:

Isabelle Schöffl

Department of Pediatric Cardiology

University Hospital Erlangen-Nuremberg

91054 Erlangen, Germany

isabelle.schoeff@me.com

\section{Introduction}

Over the past decade sport climbing has evolved into a highly professional sporting discipline and will debut at the 2021 Summer Olympic Games in Tokyo. The International Olympic 
Committee advocates that medical teams should protect and promote athlete health during training and competition. This requires routine monitoring and surveillance of individuals and a specific understanding of the physiologic adaptations inherent within the sport.

There is little doubt about the positive effects of physical activity (PA) on reducing the risk of cardiovascular disease [13]. However, elite athletes (in this article defined as being in the National Team) train between 10 and $20 \mathrm{~h}$ per week with intensities exceeding the WHO recommendations [4].

Endurance activities (long distance running, swimming), called dynamic sports reduce the systolic blood pressure by reducing the peripheral vascular resistance. This leads to an increased heart rate and volume (cardiac output). Dynamic sports therefore have a high volume load on the heart, leading to an increase of the left ventricular internal diameter and a proportional increase of wall thickness, termed eccentric left ventricular hypertrophy (LVH) [5]. Strength training on the other hand increases myocardial oxygen consumption, heart rate, blood pressure, and stroke volume, leading to an elevation of cardiac output, causing pressure load on the heart $[6,7]$. The consequence is a concentric LVH with a thickening of the ventricular wall but unchanged internal dimension [5]. In a study comparing echocardiographic measurements of elite climbers and elite Nordic skiers, climbers showed signs of concentric LVH with comparable increases of wall thickness to those of Nordic skiers but with no increase in left ventricular internal diameter [8]. However, the classification of climbing as a high-static sport based on echocardiographic measurements of the LV is insufficient. In this context, more understanding is needed about the nature of climbing with respect to its endurance characteristics.

Cardiopulmonary exercise testing (CPET) is usually employed for determining endurance performance and cardiopulmonary fitness in elite athletes. One of the best studied parameters of CPET is the as it represents an important parameter for endurance performance. It is mainly influenced by the cardiorespiratory system (i.e., heart, lungs, and blood) being able to transport $\mathrm{O}_{2}$ to the muscles [9].

Power athletes have lower values than team and endurance athletes $[9,10]$. However, this difference could be attributed to a higher cardiac output as a consequence of a higher cardiac adaptation [5] as well as to a larger oxygen carrying capacity and / or oxygen extraction by endurance athletes [10]. Still, evaluating the during a standard cardiopulmonary exercise test should allow a classification of climbing when performed by elite climbers, especially when compared to elite Nordic skiers, a sport classified as an endurance sport, when performing the same non-sport-specific test, namely a cycle test.

\section{Material and methods}

All participants as well as their respective legal guardians gave written, informed consent. The ethics committee of the University of Erlangen-Nuremberg has approved the study. Data were assembled over a 5-year period. Every athlete of the German National Junior Climbing Team is required to undergo a medical examination in order to be allowed to participate in International competitions. Some athletes were screened multiple times as they were selected for the team several years in a row. In these cases, only the most recent examination was reported for the cross-sectional approach, because we expected the greatest cardiovascular adaptations after climbing longer. Those athletes who remained on the team for a minimum duration of 2 years, the datasets of two medical examinations were compared in order to determine the cardiovascular adaptations of climbing at an elite level over that period. We compared the longitudinal data from those athletes with an age-matched control group of Nordic skiers from the German Junior National Team, a typical endurance sport. As both teams (skiing and climbing) are comparable in size and with respect to age and gender no blinding or further matching could be achieved.

Anthropometric data included: height, weight and body mass index (BMI). The anthropometric values were transferred into Z-scores (number of standard deviations below or above the reference mean) using data by Kromeyer et al. [11]. Body fat was estimated using the Jackson-Pollock method [12], this method is validated for use in children and adolescents and has been used in other studies investigating body fat in climbers [13,14]. In order to assess the history of their sports career, we recorded the age they commenced climbing, and the time spent training for climbing per week in the last year. Cardiopulmonary training, if any was also taken into account.

Each athlete underwent a standard cardiopulmonary exercise test on an electronically braked cycle ergometer (E-bike Comfort, GE Medical Systems, Chicago, USA) in form of an incremental step test. A step time of three minutes with a starting load of 80 Watts in boys and 75 Watts in girls was used, with an increase of 40 Watts for every step in boys and 25 Watts for every step in girls until physical exhaustion was achieved. The athletes pedaled at a self-chosen cadence with a minimum allowable pedaling cadence with $60 \mathrm{rpm}$. This test protocol represents our standard incremental step test protocol used for testing elite athletes [15]. We used a cycle test as it represents the standard CPET used in Europe and also represented a sport-unspecific testing method for the climbers as well as the skiers.

Capillary blood lactate (BL) (ear lobe) was collected prior to, during, and at the termination of the test and post-test (two and 
five minutes). BL was analyzed using the Lactate $\mathrm{Scout}{ }^{\circledR}(\mathrm{EKF}$, Cardiff - United Kingdom). Cardiopulmonary capacity was measured using a ZAN600® spiroergometer $(Z A N ®$, Oberthulba, Germany). A standard 12-lead exercise ECG was recorded over the entire duration of the test protocol. At the end of the test the subjective reasons for termination as well as any changes in the ECG were recorded. The standards of general performance diagnosis and stress tests were fulfilled (temperature $18-24^{\circ} \mathrm{C}$, relative humidity $30-60 \%$ ) and all participants had a minimum rest period of $>48 \mathrm{~h}$ to sport or energy demanding activity.

Statistical analysis was performed using Microsoft Excel $2000 \AA$ for data collection and SPSS $12.0 \AA$ (SPSS Inc., Chicago, IL). All measured values are reported as means and standard deviations. The Kolmogorov-Smirnov test was used to check for normal distribution. Homogeneity of variance was investigated using Levine's $F$-test. For normally distributed variables differences between the two tests with a period of at least 2 years in between were assessed with paired $t$-tests, otherwise the Wilcoxon or the Whitney-Mann- $U$-tests were used. For normally distributed variables, differences between the climbers and the cross-Nordic skiers were assessed with unpaired $t$-tests, otherwise the Wilcoxon or the Whitney-Mann- $U$-tests were used. All tests were 2 -tailed, a $5 \%$ probability level was considered significant $\left(^{*}\right)$.

\section{Results}

A total of forty-seven adolescent climbers were examined in the time frame of the study, 27 were male and 20 were female. The $z$-scores are negative for all age groups except for the group of girls at the age of 12-13 years which was made up of only one girl. There were no $z$-scores below -2.5 , the lowest was a $z$-score of -2.27 for a girl of 17 years with a height of $153.5 \mathrm{~cm}$, and for a boy of 17 years of age with a weight of $49 \mathrm{~kg}$ (height $164 \mathrm{~cm}$ ).

Fourteen climbers were reevaluated after a mean period of 27.5 months and compared to their previous data. These 8 boys and 6 girls were compared to an age- and gender-matched control group of 8 boys and 6 girls from the GJNTN who were also evaluated twice within 28.7 months' time. Both groups were comparable with respect to age, height, weight and BMI. Even though, the 14 climbers were already a mean of 16 years at the moment of the first examination, all the adolescents still showed a significant increase in height, weight, and BMI after two years. The same was true for the Nordic skiers, so that the groups did not differ with respect to the gain in height, weight or BMI.

Both boys and girls had been climbing for an average of 8 years ( $\mathrm{SD} \pm 2.9)$, the boys were training for 13 hours $(\mathrm{SD} \pm 2.9)$ and the girls for 11.5 hours $(\mathrm{SD} \pm 4)$ per week in average.

Table 1. Mean values (standard deviation in brackets) from cardiopulmonary exercise tests of 47 athletes who were seen on one occasion

\begin{tabular}{rcc}
\hline & Boys & Girls \\
\hline Work load $\left(\mathrm{Watt} \mathrm{kg}^{-1}\right)$ & $3.2(0.4)$ & $2.7(0.6)$ \\
Peak heart rate $\left(\right.$ beats $\left.\mathrm{min}^{-1}\right)$ & $181.4(14.4)$ & $183.8(12.1)$ \\
Heart rate at $V \mathrm{~T}_{1}\left(\right.$ beats $\left.\mathrm{min}^{-1}\right)$ & $156.5(11.6)$ & $157.8(11.6)$ \\
Peak borg & $18.3(1.5)$ & $18.0(1.7)$ \\
Peak lactate $\left(\mathrm{mmol} \mathrm{L}^{-1}\right)$ & $9.0(3.3)$ & $8.1(3.1)$ \\
$V \mathrm{O}_{2 \text { peak }}\left(\mathrm{ml} \mathrm{kg}^{-1} \mathrm{~min}^{-1}\right)$ & $41.3(6.7)$ & $39.8(5.4)$ \\
$V \mathrm{O}_{2}$ at $V \mathrm{~T}_{1}\left(\%\right.$ of $\left.\mathrm{VO}_{2 \text { peak }}\right)$ & $77.1(9.8)$ & $73.2(11.1)$ \\
Peak breath rate $($ breaths min & \\
Peak $\mathrm{O}_{2}$ pulse $\left(\mathrm{mL} \mathrm{beat}^{-1}\right)$ & $39.1(5.5)$ & $37.3(4.7)$ \\
Peak $\left(V_{\mathrm{E}}\right) \cdot\left(\mathrm{L} \mathrm{min}^{-1}\right)$ & $13.9(2.6)$ & $76.8(21.9)$ \\
Peak RER & $90.2(26.6)$ & $1.1(0.1)$ \\
\hline
\end{tabular}

Alternative sports for recreation or for improving cardiopulmonary fitness were undertaken by 19 of the athletes and consisted of a mean of 2 hours per week of running (14 athletes), biking (3 athletes), soccer (1 athlete) and Zumba (1 athlete), performed either randomly or twice a week. Fourteen had previously competed in other sports, mainly soccer ( 6 athletes), and track and field (4 athletes), but also swimming (1 athlete), rowing (1 athlete), gymnastics (1 athlete), tennis (1 athlete).
The values recorded for the cardiopulmonary exercise testing are recorded in Table 1. There is only one previous study which investigated the cardiopulmonary capacity of climbers with an incremental cycling test and we have included the available measurements for comparison in Table 1. Self-reported muscular fatigue was the most common cause of termination in $90 \%$ (43 out of 47) of the subjects. Out of these 43 athletes 11 stated that they had felt a shortness of breath as well as a muscular 
fatigue at the end amounting to $23 \%$ of all subjects. This was a purely subjective feeling when the participants were asked about their reason for stopping the exercise. None of the subjects terminated the test because of shortness of breath before the onset of muscular fatigue. The athletes who performed endurance sport in addition to climbing did not achieve better results in the cardiopulmonary exercise test. Four athletes were only tested sub-maximally as they had suffered from a viral infection in the 3 weeks preceding the test and their results were excluded from the presented data.

Fourteen climbers undertook the same cardiopulmonary exercise test twice within a mean of 27.8 months. Those were the only team members who remained on the team for more than two years. The other athletes did not make the team again over this time frame and were thus not evaluated a second time in the setting of the annual team examination. The reasons for not making the team again were not evaluated in this study. Of these 14 athletes 6 stated training running and/or cycling regularly for about
2 hours a week. This did not change over the period of two years. Even though their endurance training did not change, the time spent training for climbing increased significantly from 12 to 18 hours per week. The $V \mathrm{O}_{2 \text { peak }}$ of these 14 athletes did not significantly change during the 27.8 months they were on the team and neither did the values measured for the skiers (Fig. 1). Actually, there were no significant differences with respect to any of the measured variables between the two tests in the climbing group (Tab. 2). On both occasions $V \mathrm{O}_{\text {2peak }}$ was significantly lower for the climbers than for the Nordic skiers (Fig 2. and Fig. 3). The climbers had significantly lower CPET measurements than the skiers except for the respiratory exchange ratio (RER) and peak lactate which were comparable at both test occasions (Tab. 2). The RER is the ratio of $V \mathrm{CO}_{2} / V \mathrm{O}_{2}$ and thus is a direct reflection of the accumulation of acidic substrate in the system. The fact that RER values were higher in the group of climbers than in the group of Nordic skiers, highlights the fact that they pushed themselves to exhaustion at least to the same degree as the Nordic skiers if not more.

Table 2. Mean values (standard deviation in brackets) from two cardiopulmonary exercise tests of 14 climbers who were seen a second time 2 years after their first visit in comparison to data from 14 Nordic skiers who also received CPET on two separate occasions spaced two years apart

\begin{tabular}{|c|c|c|c|c|c|c|c|c|}
\hline & \multicolumn{4}{|c|}{ First Visit } & \multicolumn{4}{|c|}{ Second Visit } \\
\hline & \multicolumn{2}{|c|}{ Male } & \multicolumn{2}{|c|}{ Female } & \multicolumn{2}{|c|}{ Male } & \multicolumn{2}{|c|}{ Female } \\
\hline & Climber & $\begin{array}{l}\text { Nordic } \\
\text { Skier }\end{array}$ & Climber & $\begin{array}{l}\text { Nordic } \\
\text { Skier }\end{array}$ & Climber & $\begin{array}{l}\text { Nordic } \\
\text { Skier }\end{array}$ & Climber & $\begin{array}{l}\text { Nordic } \\
\text { Skier }\end{array}$ \\
\hline$V \mathrm{O}_{2 \text { peak }}\left(\mathrm{mL} \mathrm{kg}^{-1} \min ^{-1}\right)$ & $37.7(1.3)$ & $66.5(6.5)$ & $38.0(2.9)$ & $52.1(3.1)$ & $34.8(4.3)$ & $66.2(4.7)$ & $35.0(4.3)$ & $56.7(4.5)$ \\
\hline Work load (Watt kg-1) & $3.0(0.2)$ & $4.0(0.1)$ & $2.8(0.1)$ & $3.4(0.0)$ & $2.8(0.4)$ & $4.1(0.4)$ & $2.7(0.4)$ & $3.8(0.6)$ \\
\hline Peak heart rate (beats $\mathrm{min}^{-1}$ ) & $162(16.0)$ & $205(3.0)$ & $187(4.0)$ & $202(3.0)$ & $169(10.0)$ & $201(7.0)$ & $180(11.0)$ & $194(7.0)$ \\
\hline Peak lactate $\left(\mathrm{mmol} \mathrm{L}^{-1}\right)$ & $9.1(1.4)$ & $8.2(0.6)$ & $6.4(0.8)$ & $7.1(1.0)$ & $8.5(0.8)$ & $9.3(1.9)$ & $7.4(1.2)$ & $7.8(2.4)$ \\
\hline Peak breath rate (breaths $\mathrm{min}^{-1}$ ) & $41.0(6.0)$ & $60.0(8)$ & $37.0(6.1)$ & $62.3(8.6)$ & $34.8(4.3)$ & $66.1(4.7)$ & $33.5(5.9)$ & $68.4(9.4)$ \\
\hline Peak $\mathrm{O}_{2}$ pulse $\left(\mathrm{mL}\right.$ beat $\left.^{-1}\right)$ & $14.5(2.6)$ & $19.8(6.1)$ & $10.4(1.7)$ & $12.7(1.6)$ & $14.3(1.3)$ & $23.2(1.8)$ & $10.5(1.2)$ & $16.2(1.0)$ \\
\hline Peak $V_{\mathrm{E}}\left(\mathrm{L} \mathrm{min}^{-1}\right)$ & $84.8(38.3)$ & $133.5(26.9)$ & $62.5(9.4)$ & $91.7(9.1)$ & $76.8(21.4)$ & $151.7(24.9)$ & $58.0(10.4)$ & $100.0(9.1)$ \\
\hline Peak RQ & $1.1(0.1)$ & $1.1(0.1)$ & $1.1(0.1)$ & $1.0(0.1)$ & $1.1(0.1)$ & $1.0(0.0)$ & $1.1(0.0)$ & $1.0(0.1)$ \\
\hline
\end{tabular}




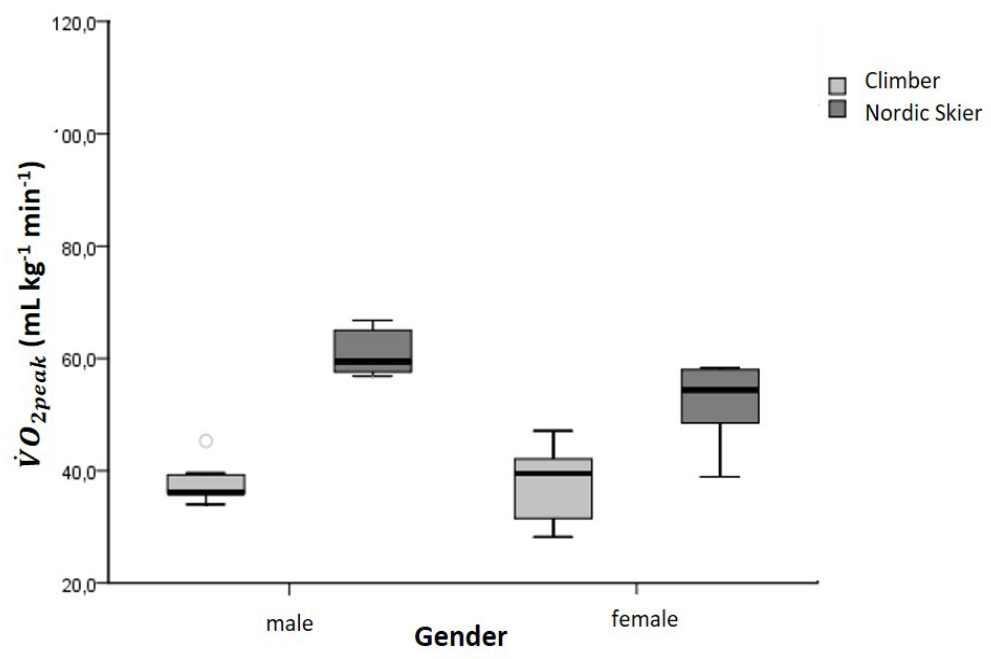

Figure 1. $V \mathrm{O}_{2 \text { peak }}$ of 14 athletes from the GJNTC in comparison to 14 athletes from the GJNTN at the first examination. The differences between both groups were significant

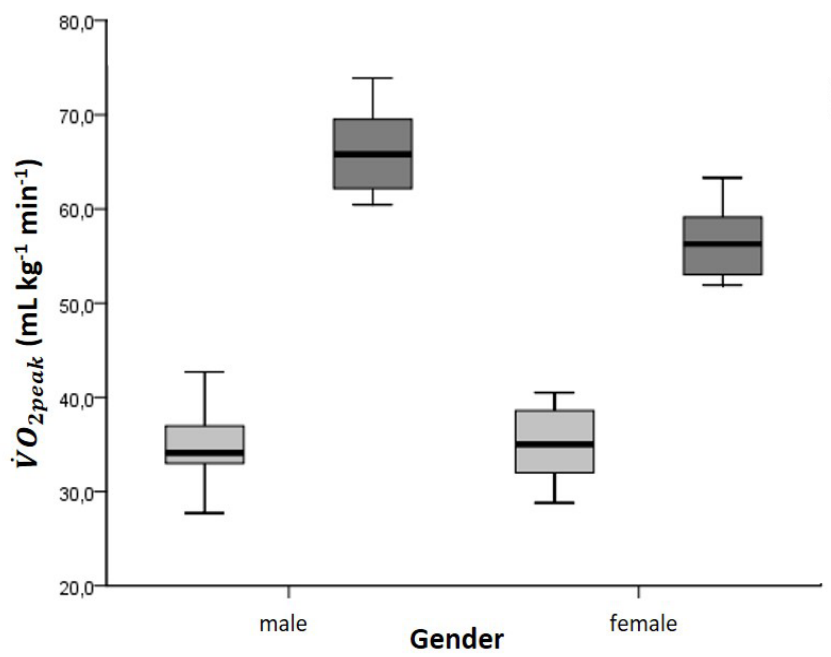

Figure 2. $\mathrm{VO}_{2 \text { peak }}$ of 14 athletes from the GJNTC in comparison to 14 athletes from GJNTN at the second examination recorded 27.8 months after the first examination. The differences between both groups remained significant

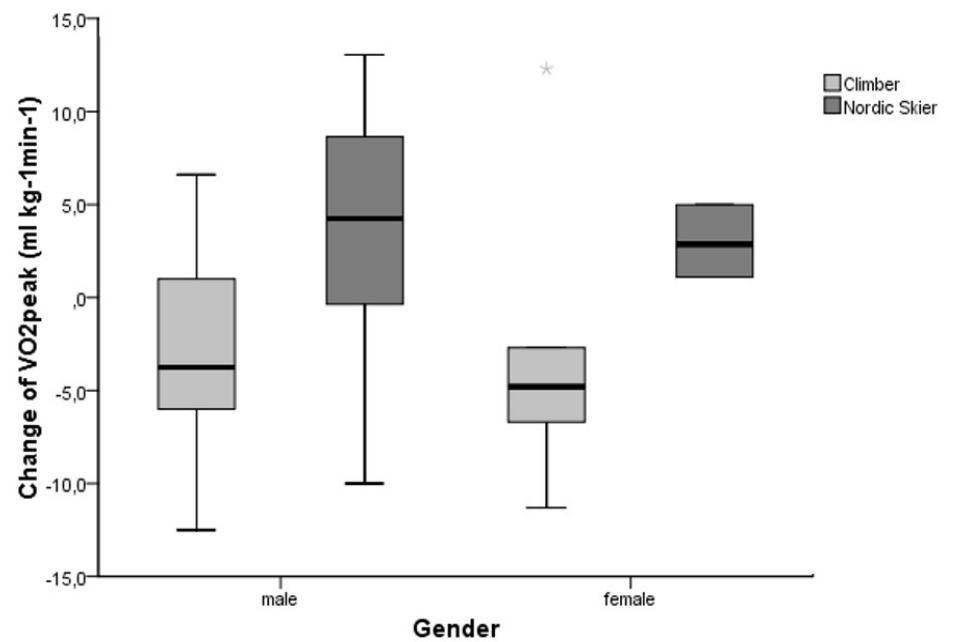

Figure 3. Changes in $V \mathrm{O}_{2 \text { peak }}$ of 14 athletes from the GJNTC in comparison to 14 athletes from the GJNTN over the period of 27.8 months. The changes were significantly different between both groups 


\section{Discussion}

The athletes of the GJNTC were smaller, slimmer and had a lower BMI than age matched population distributions as reflected by the negative $z$-scores. Watts et al. [13] recorded comparable values for height in a cohort of 13 year old male climbers (mean $162.5 \mathrm{~cm}$ ) to our sample but higher values for weight, BMI, and body fat. Therefore, our data supports the assumption that elite climbers tend to be of a smaller stature with low body fat, BMI and body weight [16] but there were no signs of pathological eating habits.

The finding that junior athletes had been climbing for an average of 8 years was unexpected as it meant that a large proportion of the athletes had commenced their climbing career aged 3 to 5 years. Less than half of the participants reported engaging in general endurance training to improve their cardiopulmonary exercise capacity.

When evaluating the CPET data from the 47 athletes who were seen on one occasion, the $V \mathrm{O}_{\text {2pak }}$ values of the boys $\left(41.3 \mathrm{~mL} \mathrm{~kg}^{-1}\right.$ $\mathrm{min}^{-1}$ ) and girls (39.8 $\mathrm{mL} \mathrm{kg}^{-1} \mathrm{~min}^{-1}$ ) were comparable to previous studies which studied adult climbers on a cycle ergometer (45 .5 mL kg ${ }^{-1} \mathrm{~min}^{-1}[17], 39.1$ to $39.7 \mathrm{~mL} \mathrm{~kg}^{-1} \mathrm{~min}^{-1}$ in men and women respectively [18].

The highest values of $V \mathrm{O}_{2 \text { peak }}$ are achieved by young elite (national team members) endurance athletes $\left(60 \mathrm{~mL} \mathrm{~kg}^{-1} \mathrm{~min}^{-1}\right)$ [19]. Adolescent sprint- and power-related athletes range between $46 \mathrm{~mL} \mathrm{~kg}^{-1} \mathrm{~min}^{-1} V \mathrm{O}_{\text {2peak }}$ for girls and $52 \mathrm{~mL} \mathrm{~kg}^{-1} \mathrm{~min}^{-1} V \mathrm{O}_{2 \text { peak }}$ for boys [19]. Aerobic capacity has been estimated to be one of the most important predictors for good results in combat disciplines and they range between $55 \mathrm{~mL} \mathrm{~kg}^{-1} \mathrm{~min}^{-1} V \mathrm{O}_{2 \text { peak }}$ for male and $46 \mathrm{~mL} \mathrm{~kg}^{-1} \mathrm{~min}^{-1} V \mathrm{O}_{2 \text { peak }}$ for female adolescents [19] and even higher in elite junior judo athletes and boxers who achieved values as high as 53-66 $\mathrm{mL} \mathrm{kg}^{-1} \mathrm{~min}^{-1} V \mathrm{O}_{2 \text { peak }}$ [20]. Team sports achieve $V \mathrm{O}_{\text {2peak }}$ values ranging between $47 \mathrm{~mL} \mathrm{~kg}^{-1} \mathrm{~min}^{-1}$ [21] and $59 \mathrm{~mL} \mathrm{~kg}^{-1} \mathrm{~min}^{-1}$ [22]. All these values were achieved during treadmill testing during which higher $V \mathrm{O}_{2 \text { peak }}$ values can be achieved than when the testing is performed on a cycle ergometer. Considering this, the climbers probably compare to sprint- and power-related athletes and those in combat or team sports. It is unclear whether a higher $\mathrm{OO}_{\text {2peak }}$ could improve their climbing as observed in combat sports because this has not been studied yet. However, if climbers reach arm-specific $V \mathrm{O}_{\text {2peak }}$ during hard climbs, as suggested previously [23], improving their maximum oxygen uptake could possibly imply an improvement in the difficulty of climbing.

The adaptation of a particular aspect of the cardiopulmonary system, like an increase of the $\mathrm{O}_{2}$ pulse $\left(\mathrm{OO}_{2} / H R\right)$, suggesting a higher cardiac output, or an improved minute ventilation $V_{\mathrm{E}}$ could not be observed in the group of elite climbers studied during the cross-sectional approach.

Interestingly, although the climbers stated muscular fatigue as the reason for terminating the CPET, a mean RER of 1.1 and a peak lactate of $8.1 \mathrm{mmol} / 1$ in girls and $9.0 \mathrm{mmol} / 1$ in boys as well as a mean heart rate of over 180 beats $\mathrm{min}^{-1}$ point towards maximal exertion. Even though the climbers in our study climbed at a comparably high level and were of comparable age they also achieved poorer maximum workloads during the cycle test with $3.2 \mathrm{~W} \mathrm{~kg}^{-1}$ (boys) and $2.7 \mathrm{~W} \mathrm{~kg}^{-1}$ (girls) in comparison to $4.2 \mathrm{~W} \mathrm{~kg}^{-1}$ [17] and a poorer mean RER (1.1 in comparison to 1.24). One explanation could be that the climbers in our study did not push themselves enough and could have gone higher. Another explanation is the different exercise protocol for cycle ergometry. Whereas we used an incremental step test, a ramp test was used in the other study [17].

The longitudinal approach of 14 athletes of whom two exercise tests spaced 2 years apart could be compared to 14 athletes from the Nordic skiers, achieved significantly higher CPET parameters except for peak blood lactate. The values of $V \mathrm{O}_{2 \text { peak }}$ were comparable to the data from previous studies for endurance athletes [19] and taking into consideration the fact that they were obtained during a cycle ergometry and not on a treadmill, even higher. This finding reflects the very high endurance level of elite Nordic skiers. It also allows for the clear differentiation between the nature of climbing and Nordic skiing. Interestingly no significant changes occurred over the time frame of two years in both groups. For the Nordic skiers this could be a consequence of their already highly trained status at the moment of the first examination, which could not further be improved in the period of two years. Although the climbers increased their climbing training significantly, the time spent on classical endurance training like running or cycling did not change. The fact that there was no change in $V \mathrm{O}_{\text {2peak }}$ after two years of climbing on the GJNTC even though the time spent training for climbing increased significantly, suggests that climbing probably does not elicit cardiopulmonary changes seen in endurance sports. A surprising finding was the relatively low heart rate of the 14 male climbers on both occasions especially in comparison with their Nordic skiing counterparts. As the RER was higher in the group of climbers and peak lactate values were comparable between both groups, it cannot be suspected that the Nordic skiers just pushed themselves harder than the climbers. However, the high standard deviation of the peak heart rate, not observed in the group of Nordic skiers suggests a big interindividual variability and indeed varied for the climbers between 153 and 200 beats min $^{-1}$.

Whereas some adaptation to the endurance nature of Nordic skiing could be seen in the increase of the cardiac output 
$\left(\mathrm{O}_{2}\right.$ pulse) as well as the minute ventilation $\left(V_{\mathrm{E}}\right)$, though not significantly, such adaptations did not occur in the group of elite climbers. As both groups were comparable to age, size, and gender, the cardiopulmonary effects of climbing may not be important enough to elicit any adaptations. However, the question remains whether an endurance training targeted to increase $V \mathrm{O}_{\text {2peak }}$ could improve the overall climbing ability. Prospective studies are needed to evaluate this effect.

\section{Limitations of the study}

Our study has several limitations. First of all, the design of the study is retrospective which is a limitation in and of itself. The collective is rather inhomogeneous and presents young athletes over a large age-span. This is based on the fact that the study entry is defined by acceptance to the German Junior National Team of Climbing which is solely based on their climbing ability. For the longitudinal design the number of athletes is comparably small. As we only wanted to include high-level climbers and compare them to high-level Nordic skiers we limited our evaluation to the members of the German Junior National Team in both sports, thus the number we were able to follow for the required period was comparably low. Also, there was no age-matched control group of sedentary subjects which is why literature data and z-scores were used for comparison.

\section{Conclusion}

In conclusion it can be said that the climbers were able to achieve values closest to athletes in team and combat sports but inferior to endurance athletes. This was also apparent when compared to a group of age- and gender-matched elite Nordic skiers. No cardiac pathologies were found during the annual medical examinations using CPET. Further studies are needed for evaluating the effect of incorporating an endurance sport into the training regimen of elite climbers.

\section{Financial Support}

This research did not receive any specific grant from funding agencies in the public, commercial, or not-for-profit sectors.

\section{References}

[1] Fiuza-Luces C, Garatachea N, Berger NA, Lucia A. Exercise is the real polypill. Physiology (Bethesda). 2013;28(5):330358. doi: 0.1152/physiol.00019.2013
[2] Ruiz JR, Castro-Piñero J, Artero EG, Ortega FB, Sjöström M, Suni J, Castillo MJ. Predictive validity of health-related fitness in youth: a systematic review. Br J Sports Med. 2009;43(12):909-923. doi: 10.1136/bjsm.2008.056499.

[3] Green DJ, O'Driscoll G, Joyner MJ, Cable NT. Exercise and cardiovascular risk reduction: time to update the rationale for exercise? J Appl Physiol. 2008;105(2):766-768. doi: 0.1152/japplphysiol.01028.2007

[4] Sabato TM, Walch TJ, Caine DJ. The elite young athlete: strategies to ensure physical and emotional health. Open Access J Sports Med. 2016;7:99-113. doi: 10.2147/OAJSM. S96821

[5] Fagard R. Athlete's heart. Heart. 2003;89(12):1455-1461.

[6] Silverthorn DU. Human Physiology: An Integrated Approach, Global ed. Melbourne: Pearson Higher Education; 2015.

[7] Barbier J, Ville N, Kervio G, Walther G, Carré F. Sports-specific features of athlete's heart and their relation to echocardiographic parameters. Herz. 2006;31(6):531-543. doi: 10.1007/s00059-006-2862-2.

[8] Schöffl I, Wüstenfeld J, Jones G, Sittrich S, Lutter Ch, Schöffl V. Athlete's Heart in elite sport climbers: cardiac adaptations determined using ECG and echocardiography data. Wilderness Environ Med. 2020;31(4):418-425. doi: 10.1016/j.wem.2020.07.005

[9] Bassett DR, Jr. Howley ET. Limiting factors for maximum oxygen uptake and determinants of endurance performance. Med Sci Sports Exerc. 2000;32(1):70-84. doi: 10.1097/00005768-200001000-00012

[10] Degens H, Stasiulis A, Skurvydas A, Statkeviciene B, Venckunas T. Physiological comparison between non-athletes, endurance, power and team athletes. Eur J Appl Physiol. 2019;119(6):1377-1386. doi: 10.1007/s00421-019-04128-3

[11] Kromeyer K, Zellner K, Jaeger U. Zur Dynamik der Wachstumsintensitat bei Jenaer Schulkindern seit 1880 [= Intensity of growth of Jena school children since 1880]. Anthropol Anz. 1995;53(4):349-357. doi: 10.1127/anthranz/53/1995/349.

[12] Jackson AS. Pollock ML. Generalized equations for predicting body density of men. Br J Nutr. 1978;40(3):497-504. doi: 10.1079/bjn19780152.

[13] Watts PB, Joubert LM, Lish AK, Mast JD, Wilkins B. Anthropometry of young competitive sport rock climbers. Br J Sports Med. 2003;37(5):420-424. doi: 10.1136/bjsm.37.5.420.

[14] Mermier CM, Janot JM, Parker DL, Swan JG. Physiological and anthropometric determinants of sport climbing performance. Br J Sports Med. 2000;34(5):359-365. doi: 10.1136/bjsm.34.5.359.

[15] Schöffl VP, Pöppelmeier O, Emmler J, Schöffl I, Küpper T, Lutter C. Ski mountaineering-Development of a sports specific Health Promotion \& Physical Activity , 2021, 14 (1), 1-8 
performance diagnosis. Sportsverletzung Sportschaden. 2018;32(4):233-242. doi: 10.1055/a-0598-7738.

[16] Watts PB. Physiology of difficult rock climbing. Eur J Appl Physiol. Apr. 2004;91(4):361-372. doi: 10.1007/s00421003-1036-7.

[17] Sheel AW, Seddon N, Knight A, McKenzie DC, Warburton DER. Physiological responses to indoor rock-climbing and their relationship to maximal cycle ergometry. Med Sci Sports Exerc. 2003;35(7):1225-1231. doi: 10.1249/01. MSS.0000074443.17247.05

[18] Rodio A, Fattorini L, Rosponi A, Quattrini FM, Marchetti M. Physiological adaptation in noncompetitive rock climbers: good for aerobic fitness? J Strength Cond Res. 2008;22(2): 359-364. doi: 10.1519/JSC.0b013e3181635cd0.

[19] Zinner C, Sperlich B, Wahl P, Mester J. Classification of selected cardiopulmonary variables of elite athletes of different age, gender, and disciplines during incremental exercise testing. Springerplus. 2015;4:544. doi: 10.1186/s40064-015-1341-8.
[20] Franchini E, Del Vecchio FB, Matsushigue KA, Artioli GG. Physiological profiles of elite judo athletes. Sports Med. 2011;41(2):147-166. doi: 10.2165/ 11538580-000000000-00000.

[21] Duncan MJ, Woodfield L, al-Nakeeb Y. Anthropometric and physiological characteristics of junior elite volleyball players. Br J Sports Med. 2006;40(7):649-651. doi: 10.1136/ bjsm.2005.021998.

[22] Sperlich B, De Marées M, Koehler K, Linville J, Holmberg H-C, Mester J. Effects of 5 weeks of high-intensity interval training vs. volume training in 14-year-old soccer players. J Strength Cond Res. 2011;25(5):1271-1278. doi: 10.1519/JSC.0b013e3181d67c38.

[23] Billat V, PAlleja P, Charlaix T, Rizzardo P, Janel N. Energy specificity of rock climbing and aerobic capacity in competitive sport rock climbers. J Sports Med Phys Fitness. 1995;35(1):20-24. 